\title{
ISOLATION AND IDENTIFICATION OF CANDIDA SPECIES IN THE PATIENTS OF UTI
}

\author{
Vaibhav Misra ${ }^{1}$, Abhishek Kumar Jain², Sanjay Singh ${ }^{3}$, Himanshi Bansal ${ }^{4}$
}

${ }^{1}$ Associate Professor, Department of Microbiology, GR Medical College, Gwalior. 2Postgraduate Student, Department of Microbiology, GR Medical College, Gwalior.

3 Postgraduate Student, Department of Microbiology, GR Medical College, Gwalior.

4 Postgraduate Student, Department of Microbiology, GR Medical College, Gwalior.

\section{ABSTRACT}

Fungal infections of the urinary tract especially those caused by Candida species are becoming increasingly common due to prolonged antibiotic use, indwelling urinary catheters, and increase in the number of immunocompromised individuals. Symptoms of Candida pyelonephritis, cystitis, prostatitis, or epididymo-orchitis are little different from those of the same infections produced by other pathogens. Candiduria occurring in critically ill patients should initially be regarded as a marker for the possibility of invasive Candidiasis. The first step in further evaluation is to verify funguria by repeating the urinalysis and urine culture.

\section{MATERIALS AND METHODS}

A total of 3381 clinically diagnosed cases of UTI from OPD and IPD of JAH and KRH Hospitals, G. R. Medical College, Gwalior were studied for one year from $1^{\text {st } J a n, ~ 2015, ~ t o ~} 31^{\text {st }}$ Dec, 2015. Urine samples were aseptically collected. Cultures were done on blood agar, MacConkey agar, CLED agar, and Sabouraud Dextrose Agar. Both bacteria and yeast were isolated. Both bacteria and yeast were identified further as per standard protocol. The isolated yeasts were included in our study for evaluation.

\section{RESULTS}

Total of $87(2.57 \%)$ cases were found positive for yeast growth. Among these, 4 species are identified with predominance of C. albicans 31.03\% (n=27), C. krusei 29.89\% ( $n=26)$, C. glabrata $24.14 \%(n=21)$, C. tropicalis $14.94 \%(n=13)$.

\section{CONCLUSION}

The finding of candiduria in a patient with or without symptoms should be neither dismissed nor hastily treated, but requires a careful evaluation, which should proceed in a logical fashion.

\section{KEYWORDS}

Candiduria, UTI, Risk Factors, Germ Tube Test, HiCrome Candida Differential Agar, Growth at $45^{\circ} \mathrm{C}$.

HOW TO CITE THIS ARTICLE: Misra V, Jain AK, Singh S, et al. Isolation and identification of candida species in the patients of UTI. J. Evolution Med. Dent. Sci. 2016;5(64):4532-4536, DOI: 10.14260/jemds/2016/1035

\section{INTRODUCTION}

Candida is a normal inhabitant in the skin, mucous membrane of the mouth, respiratory track or vagina, but may invade the other parts of the body especially in immunocompromised individuals. ${ }^{1}$ They exist predominantly in the unicellular form with both sexual and asexual forms and show thin walled ovoid cells (blastospores) that reproduce by budding. ${ }^{2}$ There are more than 150 species of Candida, but most important pathogenic species are C. albicans, C. tropicalis, C. krusei, C. glabrata. ${ }^{1}$ They may cause simple lesions to life threatening systemic infections. The most common species is C. albicans even though there has been a striking increase in the frequency of non-albicans candida in the last few years. At present, there is increase in treatment failure maybe because of drug resistance mainly in non-albicans candida.1,3,4 Thus, Candida is the $6^{\text {th }}$ most common isolated nosocomial pathogen especially from urinary tract. ${ }^{2}$

There is also important emerging evidence that Candida infection can be acquired from hospital environment. Among

Financial or Other, Competing Interest: None.

Submission 03-07-2016, Peer Review 26-07-2016,

Acceptance 02-08-2016, Published 10-08-2016.

Corresponding Author:

Dr. Vaibhav Misra,

Associate Professor,

Department of Microbiology,

Microbiology Wing,

G. R. Medical College, Gwalior-474001.

E-mail: drvaibhavmisra74@gmail.com

DOI: $10.14260 /$ jemds/2016/1035 the hospitalised population, the following categories pose a great risk in acquiring candidal infection viz., transplant patients, haematological malignancies, prolonged antibiotic therapy, catheterisation of urinary tract or vascular system, renal failure, hepatic failure, prolonged hospital stay and inter hospital transfer, ${ }^{5}$ use of immunosuppressive agents, ${ }^{6}$ extremes of age and female sex ${ }^{7}$ etc. The generous use of broad-spectrum antibiotics and other molecules have paved way for new opportunistic pathogen like Candida. In addition, diabetes mellitus and HIV infection provides a soil for candidal infection. ${ }^{8}$

Guze and Harley found funguria in only 15 of 1500 patients; more than half of these 15 patients had diabetes mellitus and were receiving antibiotics. ${ }^{9}$ A study performed by Platt et $\mathrm{al}^{10}$ showed that $26.5 \%$ of all urinary infections related to indwelling catheters were caused by fungi. Rivett et al ${ }^{11}$ found that $2 \%$ of urine specimens submitted to a hospital microbiology laboratory tested positive for yeast versus $11 \%$ of the urine samples obtained from patients in the leukaemia and bone marrow transplantation unit in the same hospital. Therefore, the prevalence of candiduria varies considerably in the hospital setting and is most prevalent among patients in the Intensive Care Unit (ICU). ${ }^{11,12}$

Candiduria is a relatively rare finding in otherwise healthy people. ${ }^{13}$ When yeast like organisms are discovered in the urine, the major decision that must be made is whether or not this signifies infection of either the upper or lower urinary tracts, colonisation of the bladder, or contamination 
of the urine sample. Most of the time, these yeasts are Candida species. ${ }^{14}$ Contamination can be differentiated from colonisation or infection by obtaining a new urine sample to verify funguria.6,15,16 Most patients with candiduria are asymptomatic and yeasts are noted in the urine as a serendipitous finding on a routine urinalysis or urine culture. ${ }^{17}$ In another study, the results of urine cultures were positive for 10 of 440 healthy adults, but these culture results reverted to negative when clean-catch techniques were used. 18

Most of these patients do not have a Candida Urinary Tract Infection (UTI). However, in those individuals who do have symptomatic candida infection, the symptoms are indistinguishable from those caused by bacterial infections. Cystitis is associated with dysuria, urgency, suprapubic discomfort, and rarely fever; pyelonephritis leads to fever, chills, and flank pain with or without lower tract symptoms. Oliguria, stranguria (difficult and painful urination), the passage of particulate matter, and/or pneumaturia suggest a complication such as the presence of a fungus ball.17,19 Presently, $10 \%-15 \%$ of nosocomial UTIs are caused by Candida species. ${ }^{20-23}$

The aim of our study was to isolate Candida species in culture in clinically diagnosed cases of UTI, speciate them using various methodology, and determine the prevalence of various species of Candida causing UTI in our region.

\section{MATERIAL AND METHODS}

The study was conducted after obtaining approval from institutional ethical committee and fully informed and voluntary consent were obtained from the patient and/or their attendants.

\section{Place of Study}

Mycology section, Department of Microbiology, G. R. Medical College, Gwalior, Madhya Pradesh.

\section{Type of Study}

Prospective cross-sectional study during the period of one year from $1^{\text {st } J a n, ~} 2015$ to 31 ${ }^{\text {st }}$ Dec, 2015.

\section{Inclusion Criteria}

1. All urine specimens of clinically diagnosed urinary tract infection patients attending OPD or admitted in various wards and ICU.

2. All urine samples, which are culture positive for fungal growth (Yeast only).

\section{Exclusion Criteria}

1. Those urine sample, which are culture negative (No growth).

2. Bacterial growth.

\section{Specimen Collection}

Clean catch mid-stream urine samples were collected in a sterile wide mouth leak-proof container and in catheterised patients' catheter clamp technique were used for sample collection.

\section{Transportation}

All samples were transported to the laboratory as soon as possible with mean transport time of one hour, if delay of 2 to
4 hours samples were refrigerated and more than 4 hour, then samples discarded and fresh sample were collected along with their proper requisition form.

\section{Isolation and Identification of Candida Spp.}

All urine samples were inoculated following semiquantitative technique by calibrated loop $(0.01 \mathrm{~mL})$ onto blood agar (blood agar base, HiMedia Laboratories Pvt. Ltd. Mumbai, India), MacConkey agar (HiMedia Laboratories Pvt. Ltd. Mumbai, India), and CLED agar (Cystine-LactoseElectrolyte-Deficient, HiMedia Laboratories Pvt. Ltd. Mumbai, India) medium and incubated at $37^{\circ} \mathrm{C}$ and read twice at 24 hours and 48 hours of incubation. Both bacteria and yeast were isolated. Dry creamy white opaque colonies on blood agar and tiny dry lactose fermenting pink colonies on MacConkey agar medium that resembled Candida colony were confirmed by Gram Stain. These candida isolates were subcultured on Sabouraud's Dextrose Agar (HiMedia Laboratories Pvt. Ltd. Mumbai, India) (Fig. 1. showing creamcoloured colony of Candida species on Sabouraud's Dextrose Agar media.), Corn meal agar (HiMedia Laboratories Pvt. Ltd. Mumbai, India), and HiCrome candida differential agar medium (HiMedia Laboratories Pvt. Ltd. Mumbai, India) for further identification.

Identification was carried out by performing Gram stain, germ tube test ${ }^{24}$ (Fig. 2. showing germ tube test under 400x.), chlamydospore production test ${ }^{25}$ (Fig. 3. showing chlamydospore under $400 \mathrm{x}$.), growth at $45^{\circ} \mathrm{C}^{24}$ and HiCrome candida differential agar medium ${ }^{26}$ (Fig. 4. Showing Growth of candida species on HiCrome candida differential agar. $\{1$ and 3-C. albicans, 2-C. tropicalis, 4-C. krusei, 5-C. glabrata\}) as per the CLSI guidelines.

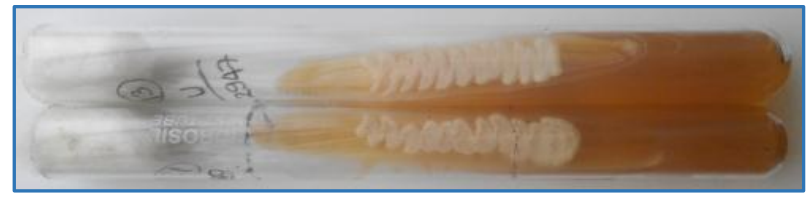

Fig. 1: Showing Cream Coloured Colony of Candida Species on Sabouraud's Dextrose Agar Media

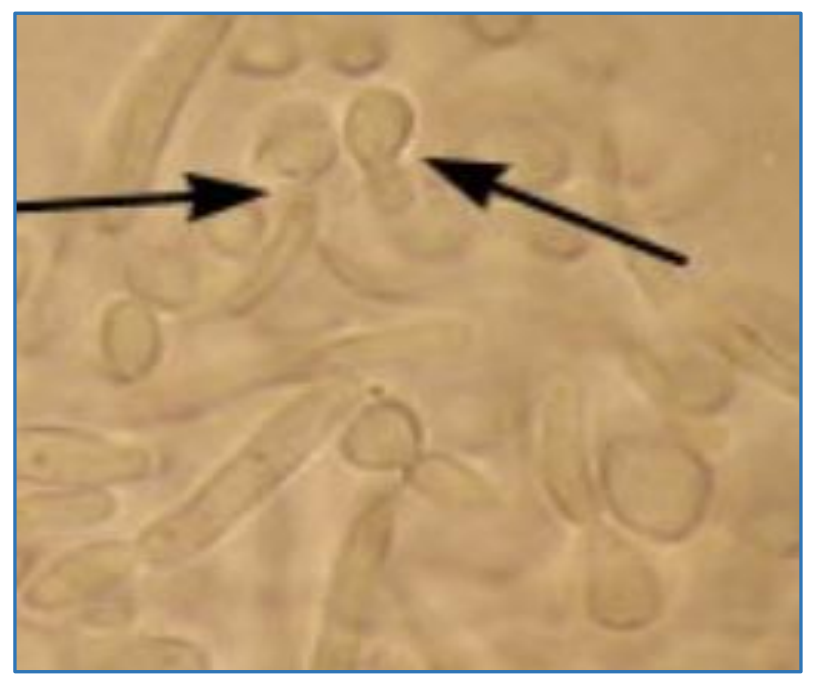

Fig. 2: Showing Germ Tube Test Under 400x. 


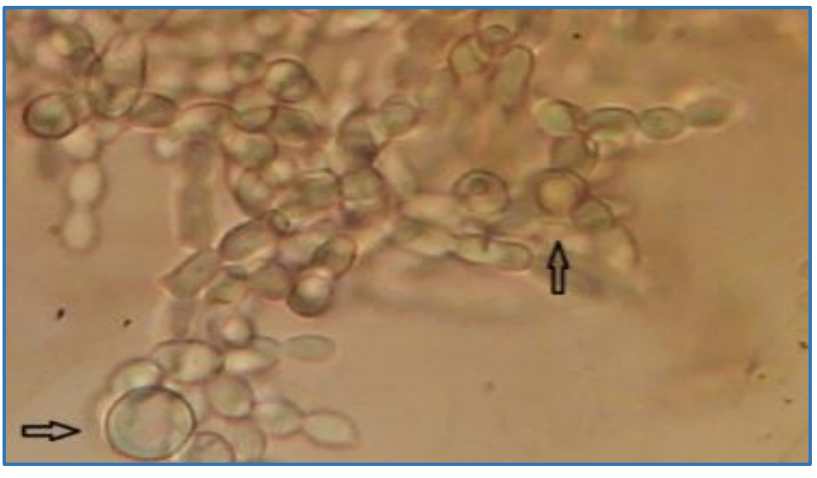

Fig. 3: Showing Chlamydospore under 400x.
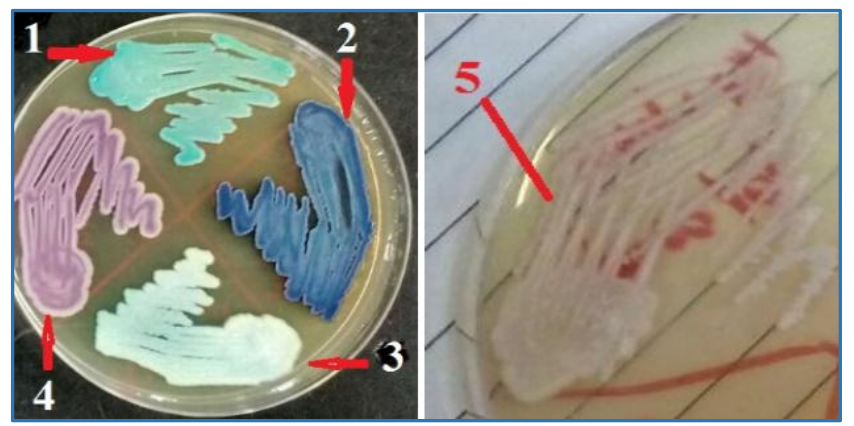

Fig. 4: Showing Growth of Candida Species on HiCrome Candida Differential Agar. (1 and 3-C. Albicans, 2-C. Tropicalis, 4-C. Krusei, 5-C. Glabrata)

Flow Chart for Isolation and Identification

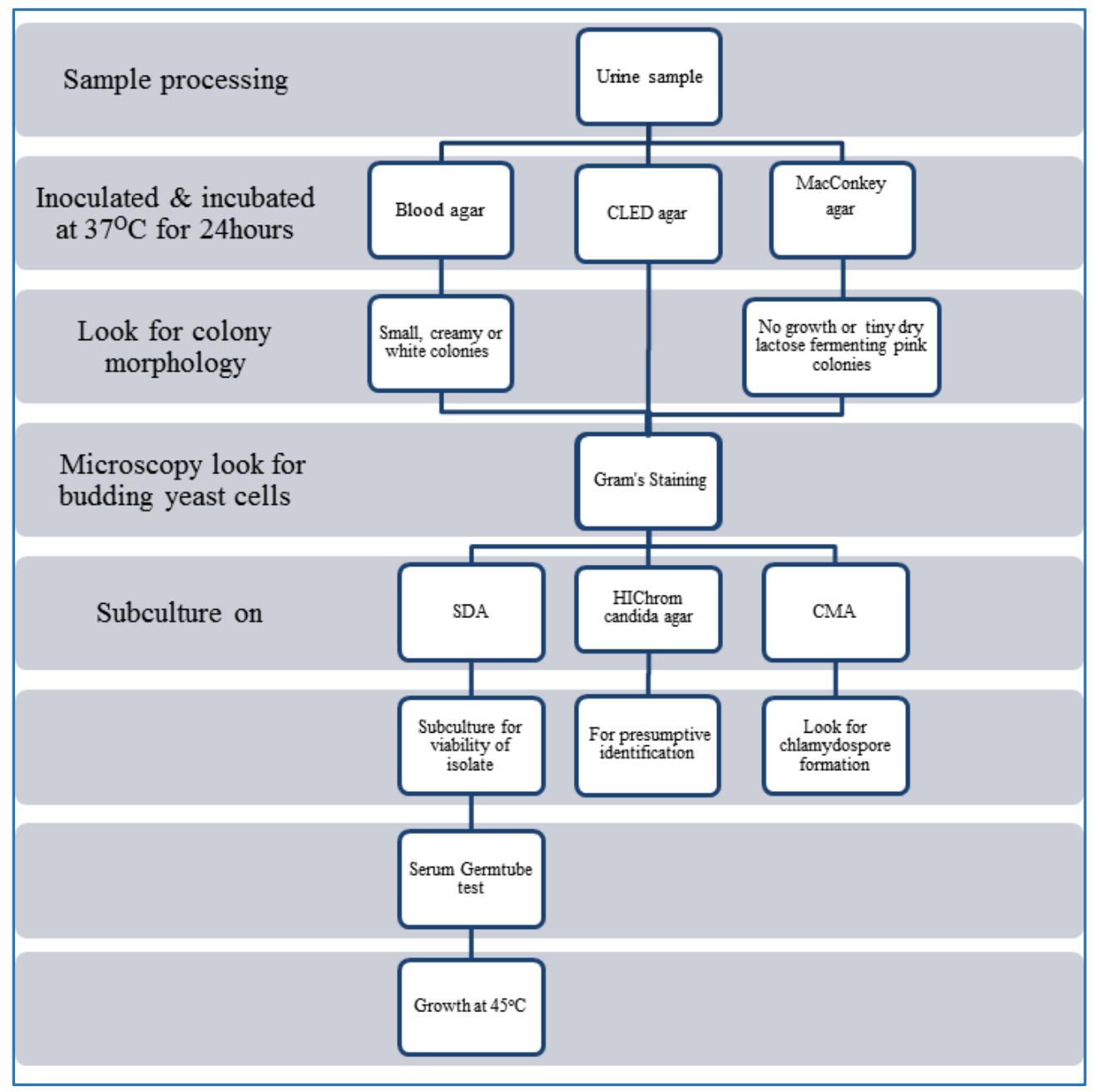

\section{RESULTS}

Total of 3381 urine sample for culture were received in the department. 2417 were culture negative, 877 were bacteriologically positive, and only 87 samples were showing yeast growth. These 87 samples were included in our study.

\begin{tabular}{|c|c|c|c|}
\hline Sl. No. & Results & No. of Samples & Percentages \\
\hline 1 & No Growth & 2417 & 71.49 \\
\hline 2 & Bacterial Growth & 877 & 25.94 \\
\hline 3 & Yeast Growth & 87 & 2.57 \\
\hline & Total & 3381 & 100 \\
\hline \multicolumn{4}{|c|}{ Table 1: Results of Urine Culture } \\
\hline
\end{tabular}

Sex and age wise distribution of cases under study depicted in Table 2 and Fig. 5 shows that there was a predominance of females reported with candiduria. In case of females, the maximum numbers of cases were in the age group of 31-60 years. Similarly, the majority of the case in males also fell in the age group of 31-60 years.

Out of 87 isolates, $58(66.67 \%)$ were isolated from female patients and $29(33.33 \%)$ from male. Male-to-female sex ratio was found to be 1:2. (Table 2).

\begin{tabular}{|c|c|c|}
\hline Sex & No. of Cases & Percentage \\
\hline Male & 29 & 33.33 \\
\hline Female & 58 & 66.67 \\
\hline \multicolumn{2}{|c|}{ Table 2: Sex-Wise Distribution of Fungal Isolates } \\
\hline
\end{tabular}


Out of 87 isolates, 69 (79.31\%) were recovered among the 31 to 60 years of age. (Fig. 5).

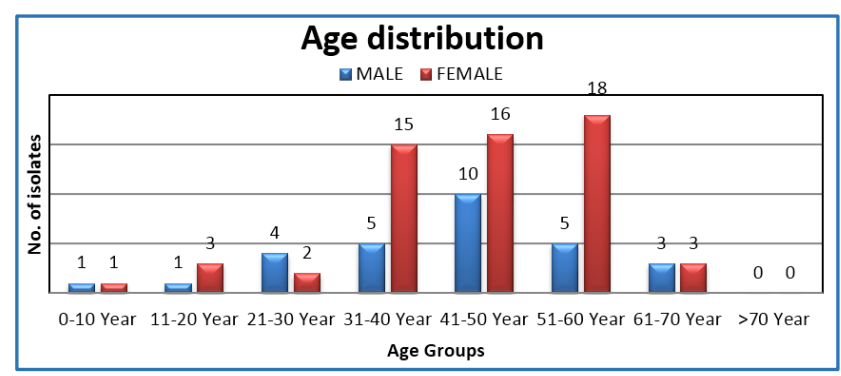

Fig. 5: Bar Diagram Showing Age-Wise Distribution of Candida Species in Male and Female.

\begin{tabular}{|c|c|c|l|l|c|c|}
\hline & Sex & \multicolumn{2}{|c|}{ Male } & \multicolumn{2}{c|}{ Female } & \multirow{2}{*}{ Total } \\
\cline { 2 - 6 } & Type of Isolate & C. albicans & Non-Albicans Candida & C. albicans & Non-Albicans Candida & \\
\cline { 2 - 6 } & No. of Isolates & $11(12.64 \%)$ & $18(20.69 \%)$ & $16(18.39 \%)$ & $42(48.28 \%)$ & 87 \\
\hline Sl. No. & Risk Factors & & & & & \\
\hline 1. & Urinary Catheter & $7(12.96 \%)$ & $12(22.22 \%)$ & $10(18.52 \%)$ & $25(46.30 \%)$ & $54(61.8 \%)$ \\
\hline 2. & Antibiotic Use & $9(19.15 \%)$ & $14(29.79 \%)$ & $11(23.40 \%)$ & $13(27.66 \%)$ & $47(54.4 \%)$ \\
\hline 3. & Diabetes & $5(12.82 \%)$ & $7(17.95 \%)$ & $10(25.64 \%)$ & $17(43.59 \%)$ & $39(44.4 \%)$ \\
\hline 4. & ICU Stay & $5(21.73 \%)$ & $6(26.09 \%)$ & $6(26.09 \%)$ & $6(26.09 \%)$ & $23(26.4 \%)$ \\
\hline 5. & $\begin{array}{c}\text { Age Between } \\
\text { 31-60 Years }\end{array}$ & $7(10.14 \%)$ & $13(18.84 \%)$ & $12(17.39 \%)$ & $37(53.62 \%)$ & $69(79.31 \%)$ \\
\hline \multicolumn{7}{|c|}{ Table 3: Sex-Wise Distribution of C. Albicans and Non-Albicans Candida and their Associated Risk Factors } \\
\hline
\end{tabular}

Total of 87 candida isolates, 4 species are identified with predominance of C. albicans $31.03 \%(\mathrm{n}=27)$, C. krusei $29.89 \%$ $(n=26)$, C. glabrata $24.14 \%(n=21), \quad$. tropicalis $14.94 \%$ $(n=13)$. (Table 4, Fig. 6).

\begin{tabular}{|c|c|c|}
\hline Fungal Isolates & No. of Isolates & Percentage \\
\hline C. Albicans & 27 & 31.03 \\
\hline C. Krusei & 26 & 29.89 \\
\hline C. Glabrata & 21 & 24.14 \\
\hline C. Tropicalis & 13 & 14.94 \\
\hline Total & 87 & 100 \\
\hline \multicolumn{3}{|c|}{$\begin{array}{c}\text { Table 4: Percentage of Various Candida Species Isolated } \\
\text { from Urine }\end{array}$} \\
\hline
\end{tabular}

\section{Distribution of Candida species}

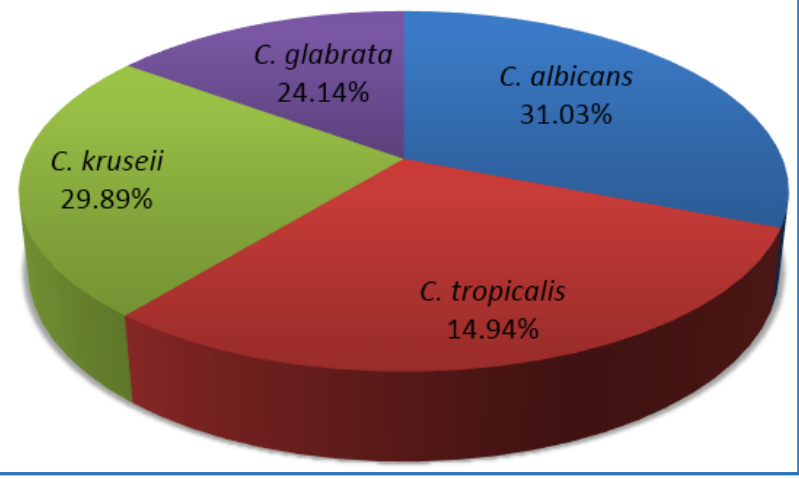

Fig. 6: Pie Diagram of Distribution of Candida Species

\section{DISCUSSION}

In the present study, the incidence of candiduria was found to be $2.57 \%$. The incidence of candiduria in patients admitted in various ward and ICU of tertiary care hospital in Bathinda,
Out of 87 isolates, 27 isolates were positive for germ tube test and growth at $45^{\circ} \mathrm{C}$ on SDA media indicating all 27 isolates were $\mathrm{C}$. albicans.

Out of 87 isolates, 27 (31.03\%) were C. albicans and 60 $(68.97 \%)$ were non-albicans candida (NAC). Common predisposing condition included urinary catheter 61.8\% patients using antibiotics $54.4 \%$, diabetes in $44.5 \%$, ICU stay in $26.4 \%$, age group of 31 to 60 year $(79.31 \%)$ were more commonly affected. (Table 3 ).
Punjab was 5.3\% as studied by Mahajan A. et al.27 In a study by Rivett et al, the incidence of candiduria among the urine

specimens submitted to a hospital microbiology laboratory was $2 \% .{ }^{11}$ However, studies conducted by Kobayashi, Claudia et $\mathrm{al}^{2}{ }^{28}$ and N. Febre V. Silva et al ${ }^{23}$ higher incidence of candiduria were reported $22 \%$ and $18.6 \%$ respectively. Our study is in accordance with the study of Rivett et al11 where incidence of candiduria was $2 \%$. Therefore, the prevalence of candiduria varies considerably in the hospital setting.

In the present study, it was observed that incidence of candiduria was reported higher among the females (66.67\%) than males (33.33\%). Mahajan A. et al ${ }^{27}$ reported $74 \%$ females and 26\% males had Candiduria. In a study, N. Safdar et $\mathrm{al}^{29}$ found that $77 \%$ females had candiduria. N. Jain et al ${ }^{30}$ observed that $77.4 \%$ females had candiduria. However, Kobayashi et al ${ }^{28}$ reported female incidence to be $57.8 \%$. Kauffman CA et al $^{7}$ reported $59.9 \%$ females with candiduria Hence, all studies done in different parts of the world show that females have more predilections towards candiduria most probably due to short urethra in females.

In the present study, out of 87 Candida isolates isolated form urine specimens, C. albicans predominated 31.03\% followed by C. krusei $29.89 \%$, C. glabrata $24.14 \%$, and C. tropicalis $14.94 \%$. Similarly, Mahajan A. et al27 reported 34\% of C. albicans followed by C. dubliniensis (31\%), C. krusei $(19 \%)$, C. tropicalis (15\%), and C. glabrata (1\%). Kobayashi et al ${ }^{28}$ reported incidence of $\mathrm{C}$. albicans to be $35.6 \%$, C. tropicalis $22 \%$. N. Safdar et $\mathrm{al}^{29}$ in their study reported incidence of C. albicans to be $35 \%$, C tropicalis $1 \%$, C. glabrata $53 \%$, C. krusei $1 \%$, and C. parapsilosis to be $4 \%$. So, it is fair to assume that Candida albicans is the commonest species isolated.

In the present study, common predisposing condition included urinary catheter $61.8 \%$, patients using antibiotics $54.4 \%$, diabetes in $44.5 \%$, ICU stay in $26.4 \%$, age between 31 
to 60 year and sex that was affected more is female that is $66.67 \%$. According to Navin Paul et al, ${ }^{31}$ incidence of various predisposing factors was catheterisation $66.6 \%$, intake of antibiotics $47.61 \%$, diabetes $38.09 \%$, and surgery in $38.09 \%$. That is in accordance to the present study. Kobayashi et al ${ }^{28}$ reported incidence of various predisposing factors was: intake of antibiotics $100 \%$, urinary catheter was present in $84.4 \%$, surgical procedure in $66.7 \%$.

\section{CONCLUSION}

The present study and several similar studies show that Candida albicans was the predominant isolate. Over the last three decades, an increase in the prevalence of candiduria as well as in the incidence of candida UTI are associated with certain risk factors, which are use of antibiotics, urinary catheterisation, diabetes mellitus, patients undergoing surgery, and female sex. In this study, a fair idea is obtained about the predisposing factors and epidemiological data of our study can serve as a template for the development of local guideline for making diagnosis of Candiduria.

The finding of candiduria in a patient with or without symptoms should be neither dismissed nor hastily treated, but requires a careful evaluation, which should proceed in a logical fashion.

\section{REFERENCES}

1. Rudramurthy KG, Kumaran R, Geetha RK. Phenotypic characterisation and antifungal susceptibility pattern of candida sp isolated from a tertiary care centre. J of Evolution of Med and Dent Sci 2014;3(9):2094-7.

2. Lal BY, Kalyani M. Phenotypic characterisation of candida species and their antifungal susceptibility from a tertiary care centre. JPBMS 2011;11(12):1-5.

3. Pfaller MA, Rex JH, Rinaldi MG. Antifungal susceptibility testing: technical advances and potential clinical applications. Clin Infect Dis 1997;24(5):776-84.

4. Chakrabarthi A, Ghosh A, Kanta A, et al. In vitro antifungal susceptibility of candida. Indian J Med Res 1995;102:13-19.

5. Hoepelman AIM. Infectious disease. In: Cohen J, Powderly WG, eds. 2nd ed. Edinburg: Mosby Harcourt Publishers Limited, Chapter-237, 2004.

6. Fisher JF, Chew WH, Shadomy S, et al. Urinary tract infections due to candida albicans. Rev Infect Dis 1982;4(6):1107-18.

7. Kauffman CA, Vazquez JA, Sobel JD, et al. Prospective multicenter surveillance study of funguria in hospitalised patients. Clin Infect Dis 2000;30(1):14-8.

8. Segal E, Topley DE. Wilson's microbiology and microbial infections. In: Merz WG, Hay RJ, eds. 10 $0^{\text {th }}$ ed. London: Hodder Arnold Publishers Ltd 2005:5.

9. Guze LB, Harley LD. Fungus infections of the urinary tract. Yale J Biol Med 1958;30(4):292-305.

10. Platt R, Polk BF, Murdock B, et al. Risk factors for nosocomial urinary tract infection. Am J Epidemiol 1986;124(6):977-85.

11. Rivett AG, Perry JA, Cohen J. Urinary candidiasis: a prospective study in hospitalised patients. Urol Res 1986;14(4):183-6.

12. Schaberg DR, Culver AH, Gaynes RP. Major trends in the microbial aetiology of nosocomial infection. Am J Med 1991;91(3B):72S-5.
13. Lundstrom $\mathrm{T}$, Sobel J. Nosocomial candiduria: a review. Clinical Infectious Diseases 2001;32(11):1602-7.

14. Kauffman CA, Fisher JF, Sobel JD, et al. Candida urinary tract infections-diagnosis. Clin Infect Dis 2011;52(Suppl6):S452-6.

15. Sobel JD. Management of asymptomatic candiduria. Internat J Antimicrob Agents 1999;11(3-4):285-8.

16. Fisher JF. Candiduria: when and how to treat it. Curr Infect Dis Rep 2000;2(6):523-30.

17. Harbach LB, Burkholder GV, Goodwin WE. Renal candidiasis. A cause of anuria. Br J Urol 1970;42(3):25864.

18. Schoenbeck J, Ansehn S. The occurrence of yeast-like fungi in the urine under normal conditions and in various types of urinary tract pathology. Scand J Urol Nephrol 1972;6(2):123-8.

19. Tennant FS, Remmers AR, Perry JE. Primary renal candidiasis. Associated perinephric abscess and passage of fungus balls in the urine. Arch Intern Med 1968;122(5):435-40.

20. Storfer SP, Medoff G, Fraser VJ, et al. Candiduria: retrospective review in hospitalised patients. Infect Dis Clin Pract 1994;3(1):23-9.

21. Jacobs LG, Skidmore EA, Freeman $\mathrm{K}$, et al. Oral fluconazole compared with bladder irrigation with amphotericin B for treatment of fungal urinary tract infections in elderly patients. Clin Infect Dis 1996;22(1):30-5.

22. Phillips JR, Karlowicz MG. Prevalence of candida species in hospital-acquired urinary tract infections in a neonatal intensive care unit. Paediatr Infect Dis J 1997;16(2):190-4.

23. Febre N, Silva V, Medeiros EA, et al. Microbiological characteristics of yeasts isolated from the urinary tract of intensive care unit patients undergoing urinary catheterisation. J Clin Microbiol 1999;37(5):1584-6.

24. Marinho SA, Teixeira BA, Santos OS, et al. Identification of candida spp. by phenotypic tests and PCR. Brazilian Journal of Microbiology 2010;41(2):286-94.

25. Balish E. Chlamydospore production and germ-tube formation by auxotrophs of candida albicans. Applied Microbiology 1973;25(4):615-20.

26. Nadeem SG, Hakim ST, Kazmi SU. Use of CHROMagar candida for the presumptive identification of candida species directly from clinical specimens in resourcelimited settings. Libyan J Med 2010;5.

27. Mahajan A, Kaur N, Kaur A, et al. Isolation, identification, and antifungal susceptibility pattern of candida spp isolated from UTI cases in a tertiary care hospital. Sch J App Med Sci 2015;3(5E):2146-52.

28. Kobayashi CC, de Fernandes OF, Miranda KC, et al. Candiduria in hospital patients: a study prospective. Mycopathol 2004;158(1):49-52.

29. Safdar N, Slattery WR, Knasinski V, et al. Predictors and outcomes of candiduria in renal transplant recipients. Clin Infect Dis 2005;40(10):1413-21.

30. Jain N, Kohli R, Cook E, et al. Biofilm formation by and antifungal susceptibility of candida isolates from urine. Applied and Environ Microbiol 2007;73(6):1697-703.

31. Paul N, Mathai E, Abraham OC, et al. Emerging microbiological trends in candiduria. Clin Infect Dis 2004;39(11):1743-4. 